\title{
Formação de professores: possibilidades e desafios do trabalho docente na contemporaneidade
}

\author{
Teacher formation: opportunities and challenges of \\ teaching activity in contemporary
}

\section{Romilda Teodora Ens ${ }^{[a]}$, Maria Lourdes Gisi ${ }^{[b]}$, Ana Maria Eyng ${ }^{[c]}$}

[a] Pesquisadora associada da Fundação Carlos Chagas, professora e pesquisadora no Programa de Pós-Graduação em Educação da Pontifícia Universidade Católica do Paraná (PUCPR), Curitiba, PR Brasil, e-mail: romilda.ens@pucpr.br

[b] Professora e pesquisadora no Programa de Pós-Graduação em Educação da Pontifícia Universidade Católica do Paraná (PUCPR), Curitiba, PR - Brasil, e-mail: maria.gisi@pucpr.br

[c] Professora e pesquisadora no Programa de Pós-Graduação em Educação da Pontifícia Universidade Católica do Paraná (PUCPR), Curitiba, PR - Brasil, e-mail: ana.eyng@pucpr.br

\section{Resumo}

O objetivo desta investigação é compreender as relações entre as políticas de formação de professores e as representações sociais de estudantes de Pedagogia sobre o trabalho docente. A análise do trabalho docente, a partir das representações de estudantes de um curso de Pedagogia, contemplou as razões que levaram os estudantes a escolher esse curso e como veem sua vida futura como profissional. As diretrizes políticas têm importância 
na construção da imagem do pedagogo ao especificarem as suas funções profissionais e, neste caso, elas reforçam a função da docência como central, pois embora a gestão e a pesquisa estejam contempladas, não são essas atividades que caracterizam a profissão do pedagogo. Nas representações do grupo de estudantes se evidencia uma mescla entre traços positivos e negativos na configuração da imagem que revelam, prevalecendo uma imagem idealizada sobre a profissão. A ênfase na docência, hoje presente nas Diretrizes Curriculares Nacionais e, também, nos dados coletados com os estudantes, pode ter o seu enraizamento mais relacionado à representação da profissão presente na sociedade e ao fato de que a maioria dos participantes já exerce a docência na educação infantil e pode ser motivada, também, pelo fato de as Diretrizes Curriculares Nacionais serem ainda recentes, pois as demais atividades dos pedagogos, indicadas nessas diretrizes, não foram significativas nas respostas. Dentre essas atividades estão: formação continuada; trabalho com a diversidade cultural no currículo; atuar com diversos grupos étnicos, raciais, pessoas com deficiência, violência e bullying, etc.

Palavras-chave: Formação de professores. Representações sociais. Trabalho docente.

\section{Abstract}

The goal of this research is to understand the relationships between policies for teacher education and the social representations of Pedagogy students about the teaching activity. The analysis of teachers activit from the representations of students of a pedagogy course contemplated the reasons why students choose the Faculty of Education and how they see their future life as a professional. The policy guidelines are important in building the image of the pedagogue when specifying their official duties and in this case they reinforce the function of teaching is central, because although the management and research are covered, these are not activities that characterize the profession of teacher. In the representations of the group of students shows a mixture of positive and negative traits in shaping the image that show, prevailing over an idealized image of the profession. The emphasis on teaching, present today in the National Curriculum Guidelines and also present the data collected from the students may have its roots more related to the representation of the profession in this society and the fact that most participants already in the teaching exercises early childhood education and may also be motivated by the fact that the National Curriculum Guidelines are still fresh, as 
other activities of the educators indicated in these guidelines were not significant in the responses. Activities such as continuing education; working with cultural diversity in the curriculum; working together with various ethnic, racial, people with disabilities, violence and bullying, etc.

Keywords: Teacher formation. Social representation. Teaching activit.

\section{Introdução}

Neste trabalho se busca investigar como as políticas de formação de professores se relacionam com as representações sociais sobre o trabalho docente de alunas de um curso de Pedagogia. Consideram-se, para fins deste trabalho, as representações sociais na perspectiva de Veronese e Guareschi (2007, p. 9), que as entende como sendo a mediação entre: “o saber pregresso dos sujeitos sociais e as ressignificações atribuídas a esses conhecimentos no cotidiano, a partir das interações com as instituições, com a mídia, com os diferentes grupos, com o sistema econômico e todas as dimensões que constituem o mundo vivido". Em se tratando da profissão do professor, pode-se afirmar que a construção da sua imagem tem forte relação com as políticas educacionais formuladas e implementadas, além do contexto socioeconômico e cultural que cerca a profissão.

Considera-se que a imagem que tem acompanhado a profissão desde o seu surgimento representa-a como uma atividade fundamental para a ascensão social dos indivíduos e para o desenvolvimento da sociedade, sendo também considerada uma atividade destinada a mulheres, com forte componente vocacional, portanto, sem necessidade de salários compatíveis com a complexidade da tarefa. Essa é, grosso modo, a imagem da professora de educação infantil e séries iniciais que tem se perpetuado no decorrer dos tempos. Certamente, a valorização da docência como uma política educacional depende, em grande parte, das políticas macroeconômicas vigentes em cada época, do mesmo modo como as demais políticas sociais. 
É evidente que ao longo dos anos as profissões passam por transformações, no entanto, Lessard e Tardif (2008, p. 255-256), ao descreverem o trabalho docente na atualidade, explicam que as três concepções que se fizeram presentes nessa trajetória desde a sua origem - vocação, ofício e profissão - se interpenetram. Segundo os autores, essas concepções não se apresentam como uma sucessão de etapas históricas, mas como reveladoras das dimensões fundamentais desse trabalho. Assim, a evolução passa a ser percebida como "um processo de complexificação e de recomposição de um trabalho que tenta reconhecer e incorporar dimensões de certo modo intrínsecas à atividade docente" (LESSARD; TARDIF, 2008, p. 256).

As considerações dos estudos desses autores podem ser relacionadas aos pressupostos da Teoria das Representações Sociais, pois sua análise permite melhor compreensão da dinâmica social. Como diz Moscovici (2003), as representações dos sujeitos classificam e ligam um objeto estranho (não familiar) a uma imagem familiar, que está marcada pela história compartilhada pelo grupo, além de serem indispensáveis para a compreensão da dinâmica social e das relações entre indivíduos.

No que se refere às representações sobre a docência, Gomes (2007, p. 105) entende que a imagem social dessa profissão na contemporaneidade demonstra que ela tem sido "cada vez mais negativa". O autor, ao discutir as representações, o faz contextualizando a imagem da escola como um modelo de sociedade construído no pós-guerra, em que havia a perspectiva de atingir o pleno emprego. Nesse contexto, a escola tinha papel fundamental na formação profissional e no acesso ao emprego e, como consequência, valorizava-se mais a docência. Ser professor, nesse período, principalmente para aquele que ingressava no ensino superior, era uma das profissões que possibilitava ascensão social para todo jovem, não só os das classes menos favorecidas, como acontece hoje.

No contexto atual, com as políticas neoliberais, o conhecimento passou a ser foco de grande atenção em razão da sua importância para o desenvolvimento econômico, no entanto, com a diminuição da responsabilidade do Estado com a educação, a profissão, também, tende a ser cada vez mais desvalorizada. Essa representação negativa tem relação com a utilização de 
estratégias de "descrédito progressivo de instituições públicas em geral e supervalorização de empresas privadas como sinônimo de eficiência e racionalidade", segundo Gomes (2007, p. 105). Tal estratégia, por sua vez, vem influenciando as reformas que imputaram uma nova racionalidade à formação de professores, ao trabalho docente e à gestão das escolas.

Um dos problemas que contribui com a imagem negativa da profissão é a qualidade da educação básica, demonstrada nas avaliações de larga escala, tais como o SAEB e a Prova Brasil. Sobre isso, Brzezinski (2008a, p. 172) afirma que falta uma "política global de formação e de valorização dos profissionais da educação, com a perspectiva de construir um sistema nacional organicamente articulado entre as diferentes esferas municipal, estadual e federal". A autora entende que é preciso propiciar articulação entre formação inicial, continuada, planos de cargos e salários e condições dignas de trabalho. Portanto, tem relação indissociável com as políticas definidas para a educação.

Atualmente, a formação em Pedagogia tem como base as Diretrizes Curriculares Nacionais, aprovadas em 15 de maio de 2006 pela Resolução CNE/CP n.1/2006 (BRASIL, 2006). Segundo Brzezinski (2008a), existe concordância das entidades da área da educação de que estas representam uma conquista ao considerar que as diretrizes:

consolidam a experiência histórica construída, principalmente, ao longo dos últimos vinte anos nos Cursos de Pedagogia das Instituições Públicas de Ensino Superior, que em sua maioria desenvolvem processos formativos que articulam, na formação de professores para a educação infantil e anos iniciais do ensino fundamental, a compreensão da educação e da escola em sua multidimensionalidade, na medida em que envolvem o estudo da escola e dos sistemas de ensino, sua organização, estrutura e funcionamento e a formação básica inicial para a pesquisa em educação (BRZEZINSKI, 2008b, p. 211).

É importante ressaltar que as diretrizes têm importância na construção da imagem do pedagogo ao especificarem as suas funções profissionais, e nesse caso elas reforçam a função da docência como central, 
pois, embora a gestão e a pesquisa estejam contempladas, não são essas atividades que caracterizam a profissão do pedagogo.

Podem ser visualizados, assim, dois aspectos importantes nas representações sobre a Pedagogia: um que se refere à identidade profissional, cujas diretrizes deixam evidente ser a docência a sua função principal; e outro que se refere às condições para exercer a profissão, cujos problemas continuam presentes. O fortalecimento da profissão envolve políticas educacionais que priorizem a educação no País e que dizem respeito, em especial, à valorização do trabalho docente.

\section{Os sentidos do trabalho docente}

Ao explicar os sentidos do trabalho, Antunes (2008, p. 2, grifo do autor) adota uma concepção que enfatiza o potencial emancipador do trabalho humano, considerando que o homem como ser social precisa recusar o trabalho que aliena e infelicita. Os homens e mulheres que trabalham, diz ele, "são dotados de consciência, por conceberem previamente o desenho e a forma que querem dar ao objeto do seu trabalho". O autor explica, ainda, que, segundo Lukács (1978, p. 8 apud ANTUNES, 2008, p. 2, grifo do autor), o "trabalho é um ato consciente e, portanto, pressupõe um conhecimento concreto, ainda que jamais perfeito, de determinadas finalidades e de determinados meios". Já Gramsci, diz Antunes (2008, p. 2, grifos do autor), "acrescentou que em qualquer forma de trabalho, mesmo no trabalho mais manual, há sempre uma clara dimensão intelectual”. Explica o autor que, "anteriormente, Marx havia demonstrado que o trabalho é fundamental na vida humana porque é condição para sua existência social”.

Assim, podemos dizer que, em linhas gerais, o trabalho é um processo por meio do qual o homem se relaciona com a natureza, com seu entorno, com a sociedade, para transformá-los e ajustá-los às suas necessidades e interesses. No entanto, não se pode deixar de considerar que o trabalho pode conter duas dimensões, que, segundo Aranha e Dias (2009, p. 116), dependem das condições em que ele é realizado: "uma primeira 
dimensão construtora, emancipadora. É o trabalho concreto de Marx, voltado para a produção de coisas e para a satisfação de necessidades humanas, contribuindo para a realização do indivíduo enquanto criador e transformador de seu meio". Já a outra dimensão, de acordo com as autoras, é a do trabalho na "dimensão, alienante, opressora. [...] O trabalho torna-se algo impessoal, reduz-se a mais uma mercadoria".

Nessa perspectiva, Tardif e Lessard (2005, p. 28, 31), ao analisarem a docência como trabalho, explicam que "Marx mostrou que o processo do trabalho transforma dialeticamente não apenas o objeto, mas igualmente o trabalhador, bem como suas condições de trabalho". Em se tratando do trabalho docente, explicam os autores, este acontece em um processo de interações humanas, portanto, "ensinar é trabalhar com seres humanos, sobre seres humanos e para seres humanos". O trabalho docente, segundo Basso (1998, p. 19, grifo do autor), ao ser

concebido como uma unidade é considerado em sua totalidade que não se reduz à soma das partes, mas sim em suas relações essenciais, em seus elementos articulados, responsáveis pela sua natureza, sua produção e seu desenvolvimento. A análise do trabalho docente, assim compreendido, pressupõe o exame das relações entre as condições subjetivas - formação do professor - e as condições objetivas, entendidas como as condições efetivas de trabalho, englobando desde a organização da prática - participação no planejamento escolar, preparação de aula etc. - até a remuneração do professor.

Inúmeras são as funções que se agregam ao trabalho docente, uma vez que os professores, geralmente, constituem-se em profissionais que procuram meios para responder às exigências que a sociedade lhes impõe, fazendo uso de seus saberes, seus valores e suas habilidades para concretização da tarefa docente.

Esse contingente de profissionais da educação, como observa Oliveira (2009), vem desde o fim do século XX e início deste século sendo submetido a um processo de mudanças, denominado globalização, e consubstanciado em reformas educacionais no contexto de reestruturação do 
capital. Nesse âmbito, as reformas educacionais que ocorreram no Brasil nesse período trouxeram como características principais a regulação e o controle em decorrência da nova configuração do papel do Estado, sustentado na ideologia neoliberal, correspondendo às exigências dos organismos internacionais, com o objetivo de "transferir a educação da esfera da política para a esfera do mercado" (GENTILI, 1998, p. 19). Consequentemente, a educação passa a ser vista como mercadoria e busca atender às necessidades do mercado decorrentes do modo de produção vigente.

O que se observa é que as reformas educacionais implantadas no Brasil a partir da década de 1990 estão envoltas nessa nova racionalidade, ou seja, formação de força de trabalho para o desenvolvimento capitalista, sendo concepções e propostas muito similares àquelas que circulam no plano mundial, dentre as quais estão: descentralização, autonomia, participação da comunidade, envolvimento das famílias, além de forte ênfase no acesso, na avaliação e na eficiência da gestão escolar. É uma legislação que altera a atuação do professor no espaço escolar e em todo o sistema educacional, altera a formação inicial nas instituições de ensino superior e, por fim, repercute na profissão docente.

Diante da complexidade dos múltiplos aspectos que caracterizam e incidem nas representações sobre o trabalho docente, os profissionais sempre se questionam a respeito de "como adquirir mais habilidades e mais conhecimento", pois estes mudam constantemente. Como mostra Bauman (2008, p. 39), "nossa maneira de estar-no-mundo, nesta segunda modernidade é líquida. O mundo líquido é incerto, inseguro e vulnerável”.

Nesse contexto, podemos dizer que nas representações sobre o trabalho docente se encontram

sentimentos antagônicos que se expressam, por um lado, na admiração pelo avanço científico e tecnológico e, por outro, no que Baumann [2001] definiu como 'precariedade, instabilidade e vulnerabilidade', não necessariamente entendidos como determinações da tecnologia, mas como traços característicos de uma modernidade que se liquefaz, ao diluir as certezas da ilusão moderna no descartável, na performance e na individuação (FARTES, 2008, p. 583). 
No entanto, diante das questões enumeradas, não se pode deixar de lembrar, apoiando-se em Antunes (2008, p. 3, grifos do autor), que ao mesmo tempo em quem o trabalho é considerado "como um momento fundante da vida humana, ponto de partida no processo de humanização, por outro lado, a sociedade capitalista o transformou em trabalho assalariado, alienado, fetichizado. O que era uma finalidade central do ser social converte-se em meio de subsistência. [...] Converte-se em meio e não primeira necessidade de realização humana”.

Em relação ao trabalho docente e as reais condições de trabalho, Weber (2003), Evangelista e Shiroma (2003), Lüdke e Boing (2004), Oliveira (2004), Tardif e Lessard (2005) e Ens, Gisi e Eyng (2009) apontam os processos de precarização do trabalho, que levam à desprofissionalização e até proletarização do trabalho docente. Isso se coloca como uma grande contradição, pois se chegou ao fim do século XX com o slogan "profissionalizar o professor”, como apontam Evangelista e Shiroma (2003, p. 27).

Embora a precarização do trabalho docente ainda seja uma realidade no País, cabe salientar que o estudo realizado por Gatti e Barreto (2009, p. 17) sobre "o lugar dos professores na estrutura de emprego no Brasil”, indica que, "no Brasil, a importância dos professores no cômputo geral dos empregos formais não é menor do que nos países avançados". Explicam as autoras, que se apoiaram nos dados da Rais ${ }^{1}$ sobre o total de empregos para professores no Brasil. De acordo com a Rais, em 2006 8,4\% dos empregos no Brasil destinavam-se a professores, o que os colocava em terceiro lugar no ranking de subconjuntos de ocupações. Só que 82,6\% provinham de estabelecimentos públicos, ao que as autoras alertam:

essa enorme massa de empregos na esfera pública, provavelmente, uma das maiores do mundo, tem óbvios desdobramentos em termos de financiamentos do setor educacional, dos salários, das carreiras e das condições de trabalho docente, além, evidentemente, das repercussões na qualidade do ensino ofertado.

1 Relação Anual de Informações Sociais (Rais), base estatística do Ministério do Trabalho e do Emprego. 
As análises de Tardif e Lessard (2005, p. 22) sobre o trabalho docente evidenciam, também, ser essa uma profissão que está longe de ser periférica ou secundária, "sendo tanto por causa de seu número como de sua função, uma das principais peças da economia das sociedades modernas avançadas". Os autores complementam dizendo: "nessas sociedades, a educação representa, com os sistemas de saúde, a principal carga orçamentária dos estados nacionais".

Não somente nas sociedades avançadas, explicam Gatti e Barreto (2009, p. 15), como também nas emergentes, como o Brasil, "o setor de serviços e, no seu interior, os grupos de profissionais, cientistas e técnicos não cessam de crescer, e passam a ocupar posições de destaque em relação aos trabalhadores que produzem bem materiais, cuja presença numérica e importância relativa diminuem". Sabe-se que a importância da formação do professor e do trabalho docente é considerada pela atenção com que a economia dos países e, consequentemente, as políticas públicas tratam e definem os recursos orçamentários para a educação, pois, como dizem Gatti e Barreto (2009, p. 15), "além da importância econômica, o trabalho dos professores também tem papel central do ponto de vista político e cultural". No entanto, a valorização da docência, na atualidade, ainda não corresponde à sua importância na sociedade.

\section{Sentidos do trabalho docente nas representações de estudantes de Pedagogia}

A análise do trabalho docente, ${ }^{2}$ a partir das representações de estudantes de um curso de Pedagogia, contempla a análise de 16 entrevistas, ${ }^{3}$

2 Pesquisa realizada como parte integrante de uma rede internacional de pesquisadores associados ao Centro Internacional de Estudos em Representações Sociais, Subjetividade - Educação (CIERS-Ed) da Fundação Carlos Chagas (São Paulo, Brasil).

3 A coleta de dados teve a participação das alunas do curso de Pedagogia: Tatiane Jess Monteiro e Sueli Pereira Donato, ambas participantes do PIBIC nos anos de 2007/2008, 2008/2009 e 2009/2010. 
destacando-se as razões que levaram os estudantes a escolher o curso de Pedagogia e como veem sua vida futura como profissional, com ênfase no 'ser professor'.

A escolha da Teoria das Representações Sociais (TRS), para análise do trabalho do professor na atualidade, mostra-se bastante adequada em um contexto em que a sua formação e atuação tem ocupado grande espaço nos estudos de pesquisadores, bem como nos discursos veiculados pela mídia. Essa teoria, como indica Marková (2006, p. 53), "tem demonstrado seu poder teórico no estudo dos fenômenos que tiveram efeitos fundamentais no pensamento social e na comunicação no mundo inteiro".

Sendo o trabalho docente um tema amplamente discutido e analisado com posições diversas, as representações sociais sobre esse fenômeno podem contribuir para compreender como esse trabalho está sendo incorporado pelos futuros profissionais, estudantes de Pedagogia. Jodelet (2001, p. 22) explica que as representações sociais são "uma forma de conhecimento, socialmente elaborada e partilhada, que tem um objetivo prático e concorre para a construção de uma realidade comum a um conjunto social". Assim, possibilita a mediação na comunicação entre os indivíduos, como bem demonstra Guareschi (2007, p. 34) quando afirma: “se prestarmos atenção ao nosso agir, veremos que é impossível pensar, falar e mesmo agir, sem que por detrás, como pressuposto haja algo que tem a ver com a cultura, as crenças, os valores: é a isso que designamos de Representações Sociais". Não se pode esquecer, também, que "as pessoas são capazes, de fato, de usar diferentes modos e pensamentos e diferentes representações, de acordo com o grupo específico ao qual pertencem, ao contexto em que estão no momento" (MOSCOVICI, 2003, p. 328).

Como alerta Imbernón (2002), é fundamental à profissão docente a capacidade reflexiva como um processo coletivo, apoiada em uma formação inicial e continuada, que transcenda o ensino e possibilite espaços de participação para a adaptação às mudanças e incertezas.

$\mathrm{Na}$ investigação, ao falarem sobre a escolha profissional, as representações de 16 entrevistados confirmam aspectos de valorização da profissão, além das questões da afetividade e da influência familiar na decisão. 
Sobre a escolha profissional e a expectativa em relação ao curso, sete estudantes indicam ser 'por escolha própria', embora três possuam familiares professores dos anos iniciais do ensino fundamental; quatro, 'por influência da família'; dois, 'por falta de opção', mas 'gostaram do curso'; três porque 'já atuavam na área'. Esses dados são confirmados quando 12 estudantes dizem que 'repetiriam a escolha'; dois 'não repetiriam'; e dois 'repetiriam em outras áreas da educação, como biologia, psicologia ou outras'.

Em relação à formação recebida, a maioria diz ser um bom curso, mas sentem que não poderão encerrar sua formação profissional com apenas o curso de Pedagogia, como a estudante (01M - 24 anos) afirma: "sinto-me preparada, porém, vou fazer a pós-graduação e vou continuar, e é um bom curso", ou como diz o estudante (02N - 21 anos), foi uma formação "boa e satisfatória".

Do grupo de 16 estudantes que terminaram o curso de Pedagogia em 2009, apenas três cursaram o magistério no ensino médio. Os dados do perfil, obtidos no início das entrevistas, revelaram que uma das características marcantes dos participantes da pesquisa é a juventude. Como se pode observar, dez estudantes encontram-se na faixa etária entre 21 e 25 anos, o que evidencia o otimismo que demonstram em relação a ser professor dos anos iniciais do ensino fundamental, ao perguntar-se sobre a opção profissional.

Outro aspecto a ser ressaltado é a predominância de mulheres entre os formandos em Pedagogia no grupo investigado, tendência constada dentre aqueles que optam pela profissão professor. Como mostram os dados do IBGE, no Brasil, em 2006, 98\% dos professores da educação infantil são mulheres e no ensino fundamental de $1^{\mathrm{a}}$ a $4^{\mathrm{a}}$ série, com ensino superior, 93\% são mulheres (GATTI; BARRETO, 2009, p. 25). Na pesquisa realizada pelo CIERS-ed, com aproximadamente 3.000 alunos do $1^{\circ}$ ano de cursos de formação de professores, entre 2006 e 2007, há predominância de 93\% do gênero feminino (SOUZA; VILAS BÔAS, 2009, p. 5).

Os depoimentos de dois entrevistados comprovam que aqueles que já ingressaram no mercado de trabalho pretendem continuar na profissão e são otimistas, como mostra a fala do estudante 11, com 23 anos: 
"pretendo continuar na profissão porque me identifiquei com o curso e não me vejo trabalhando em outra coisa", ou como diz o estudante 15, com 25 anos: "é uma profissão muito gratificante". Os participantes, em sua maioria, já trabalham na profissão, seja como professor ou como estagiário em escolas. Dois estudantes que não trabalham na docência estão envolvidos desde o segundo ano do curso em Programas de Iniciação Científica - PIBIC.

Sobre a autopercepção futura como profissional, a maioria se vê como professor. Verifica-se, também, que quase $50 \%$ possuem uma autopercepção positiva da profissão. Os dados mostram que apenas um estudante não pretende ser professor e doze pretendem, pois acreditam nessa profissão e que o mundo poderá melhorar se tiver bons professores formados. Já três deles apresentam dúvidas e dizem não saber se seguirão a profissão de professor.

Nas representações sobre ser professor, manifestam uma diversidade de percepções que se enredam. Assim, existem representações que destacam o tipo de vínculo entre professor e aluno como traço fundamental, ao dizerem que "ser professor além de tudo é ser amigo" (12N - 49 anos). Existem também representações que enfatizam aspectos mais operacionais e do cotidiano da profissão:

é [...] estar ali para ensinar, para ser um mediador, passar conhecimentos, escutar o que o aluno tem para dizer. Bem tumultuado, trabalhoso bem corrido, [...] mas é bem legal (16N - 22 anos).

Enquanto para uns é "bem legal", preponderando uma imagem positiva, para outros, no ser professor, prevalece a imagem mais negativa ao dizerem que é "puxado, estressante, além de faltar uma remuneração adequada".

É um cotidiano bem puxado, temos que ter muita força de vontade e gostar muito do que se faz (13N - 22 anos).

Deveria ser muito bem remunerado para fazer o que ele faz, é um trabalho que exige muita dedicação (A. $15 \mathrm{~N}-25$ anos). 
Os traços mais negativos na imagem podem ser notados ainda na fala, que parece compreender a vocação como uma força capaz de atenuar os problemas das condições de escolha e do dia a dia de um professor, conforme diz um estudante (02N - 21 anos):

muito corrido, muita coisa em pouco tempo e não são bem pagos para isso, é realmente uma vocação ser professor de educação básica. Acho que existem duas coisas que levam a pessoa a escolher o curso, ou a vocação mesmo [...] pelo desejo de ser professor. A outra seria [...] a falta de acesso. [...] vai fazer o curso de Pedagogia ou na área da educação porque é mais barato.

Ao mesmo tempo, "ser professor", dizem alguns estudantes, está marcado por sentimentos.

Emoção é o que me vem à mente e uma grande satisfação (01M - 24 anos).

Alegria e um pouco de angústia. Porém é um sentimento de realização $(02 \mathrm{~N}$ -21 anos).

Medo e angústia por não me sentir preparada (05M - 46 anos).

É um misto, é alegria de você ter vencido, angústia de saber o que o espera (07N- 42 anos).

Ao falarem sobre a profissão docente, parecem ter uma visão mais idealizada desse trabalho, mas, ao mesmo tempo em que idealizam, demonstram insegurança, como diz um estudante (07N - 42 anos):

acredito na educação, acredito no que estou fazendo e se eu deixar de acreditar que tudo pode melhorar, um dia quem sabe tenham mais respeito com o professor. [...] vamos acreditar que isso vai mudar.

Os estudantes demonstram preocupação com o preparo para enfrentar a sala de aula, desenvolvimento de um projeto educativo que 
contribua para uma sociedade mais justa, além do enfrentamento da crise de valores e mudanças sociais e culturais.

Além de transmitir conhecimento [...] valores que a gente percebe não estar sendo trazido de casa [...] (10N - 23 anos).

Ser professor hoje em dia é muito difícil, porque a educação está cada vez mais difícil, as crianças trazem isso de casa, são costumes, valores que não existem mais [...] (03M - 46 anos).

Além disso, eles têm consciência de que formação inicial e continuada são aspectos fundamentais e complementares no trabalho docente. No entanto, também reconhecem que as condições de trabalho e a complexificação do trabalho docente transformaram as atribuições da profissão na atualidade.

Algumas dessas características podem ser confirmadas pelos estudantes entrevistados ao explicitarem o que é "ser professor" hoje, voltando-se para a idealização da profissão, sem deixar de lado a questão social apontada por Carnoy (1993 apud OLIVEIRA, 2009).

É uma coisa bem gratificante, posso dizer mágica (08N - 23 anos).

É aprender dia após dia (09N - 22 anos).

Buscar mudanças, mudança social, um outro olhar (04M - 39 anos).

Observa-se que as características indicadas por Brzezinski (2008c) ainda não são objeto de preocupação dos estudantes de curso de Pedagogia, pois há inclusive dificuldade de manter-se a participação no Centro Acadêmico do curso. Alguns aspectos parecem contribuir para a pouca conscientização da participação em órgãos de classe, mesmo durante o espaço da formação, uma vez que quase todos os alunos que frequentam cursos de formação de professores são alunos trabalhadores. Eles necessitam dos estágios remunerados para contribuírem com o pagamento da mensalidade do curso, além de pagarem seu deslocamento. 
Embora se evidencie, assim, uma mescla entre traços positivos e negativos na configuração da imagem que os estudantes revelam, prevalece uma imagem idealizada sobre a profissão. É natural que os estudantes que pretendem se professores - e até mesmo os que já se encontram no exercício da docência - tenham uma imagem idealizada da profissão, pois em muitas situações, como aponta a pesquisa, a escolha foi uma opção de vida relacionada a uma imagem preexistente de que se trata de uma atividade nobre e voltada para a promoção de pessoas. Contudo, observa-se também que as respostas já demonstram insatisfação com as condições de trabalho e a valorização profissional.

\section{Considerações finais}

A análise dos dados da pesquisa de campo revelou que, para as estudantes de Pedagogia, a constituição do trabalho docente tem forte componente vocacional, relacionado ao papel do educador e da sua atuação, especificamente, em sala de aula. Os discursos que emergem das justificativas mostram que alguns atributos, como responsabilidade, capacidade, sabedoria, diálogo, quando integram a docência, fortalecem a função identitária do trabalho docente. Não se evidencia atribuição de significado importante ao desenvolvimento profissional, o que incluiria a formação continuada, assim como as inúmeras atribuições além da sala de aula, que pedagogos exercem na atualidade, conforme indicado nas diretrizes curriculares.

A ênfase na docência, hoje presente nas Diretrizes Curriculares Nacionais e presente, também, nos dados coletados com os estudantes, pode ter o seu enraizamento mais relacionado à representação da profissão presente na sociedade e ao fato de que a maioria das participantes já exerce a docência na educação infantil. Tal constatação pode ser motivada pelo fato de as Diretrizes Curriculares Nacionais serem ainda recentes, pois as demais atividades dos pedagogos indicadas nessas diretrizes não foram significativas nas respostas. Atividades tais como formação continuada, trabalho com a diversidade cultural no currículo, atuar junto 
com diversos grupos étnicos, raciais, pessoas com deficiência, violência e bullying, etc.

As políticas educacionais nas representações dos estudantes de Pedagogia podem estar, como diz Marková (2006, p. 233), apoiadas em Moscovici (1976, 1979), em relação ao trabalho docente como "uma imagem-e-fundo, não por causa de uma característica que seja, a priori, importante em algum sentido, mas porque por alguma razão, esta característica se torna significante", pois as "representações se encontram fora do alcance, da vontade e do poder dos indivíduos" (SOUZA et al., 2007, p. 99-100).

Além disso, como destacam Evangelista e Shiroma (2003), o reconhecimento da formação docente como deficitária gerou na legislação educacional a exigência de um novo perfil de professor que atendesse à sua "profissionalização", colocada como estratégica para a educação da população brasileira. Alertam as autoras, que o forte apelo à profissionalização, ao mesmo tempo em que foi recebido com certa positividade, também alertou alguns educadores quanto às contradições dos dispositivos legais. Por exemplo:

elevou-se a formação docente ao nível superior - por meio da criação dos institutos superiores de Educação -, mas propôs-se uma formação mais abreviada, inclusive pela extinção futura da formação de nível médio; centrou-se a formação na pesquisa, mas retiraram-na da universidade e se deu proeminência à pesquisa sobre a prática docente, com forte viés pragmático (EVANGELISTA; SHIROMA, 2003, p. 29).

Como afirma Campos (2003, p. 84, 87), "profissionalizar os professores tornou-se a palavra de ordem". Contudo, segundo a autora, mesmo ao encontrar em todos os documentos examinados a profissionalização como o principal objetivo da reforma educacional brasileira, observou-se que os movimentos de aprofundamento da formação caminham em uma direção técnica. Os documentos produzidos no período de 1999 a 2003 mostram um deslocamento da noção de 'professor reflexivo' para a de 'professor competente', o que reforça e legitima a competência técnica como fundante da profissionalização. 
Outro aspecto evidente é que a promessa da profissionalização no campo docente não atendeu ao que a palavra promete, ou seja, promover a qualidade da função docente e a valorização social. Ela promoveu "a superficialização da formação, a burocratização do trabalho docente, a competição interpares, a segmentação da categoria", como apontam Evangelista e Shiroma (2003, p. 43).

No que tange às representações das futuras professoras sobre a profissão, observou-se, por um lado, a imagem de uma profissão idealizada no que se refere à sua finalidade e relevância social e, por outro, a percepção da desvalorização no que se refere à falta de reconhecimento do trabalho realizado.

\section{Referências}

ANTUNES, R. Século XXI: nova era da precarização estrutural do trabalho? In: SEMINÁRIO NACIONAL DE SAÚDE MENTAL E TRABALHO, 1., 2008, São Paulo. Anais... São Paulo: Seminário Nacional de Saúde Mental e Trabalho, 2008. Disponível em: <www.fundacentro.gov.dominios/CTN>. Acesso em: 29 maio 2010.

ARANHA, A. V. S.; DIAS, D. S. O trabalho como princípio educativo na sociabilidade do capital. In: MENEZES NETO, A. J. de et al. Trabalho, política e formação humana: interlocuções com Marx e Gramsci. São Paulo: Xamã, 2009. p. 115-128.

BASSO, I. S. Significado e sentido do trabalho docente. Cadernos CEDES, Campinas, v. 19, n. 44, p. 19-32, 1998.

BAUMAN, Z. Múltiplas culturas, una sola humanidad. Buenos Aires: Katz, 2008. BRASIL. Ministério de Educação e do Desporto. Conselho Nacional de Educação/ Conselho Pleno. Resolução CNE/CP 1, de 15 maio de 2006. Institui diretrizes curriculares nacionais para o curso de graduação em Pedagogia, licenciatura. Diário Oficial [da] República Federativa do Brasil, Poder Legislativo, Brasília, DF, 15 maio 2006, seção 1, p. 11. Disponível em: <http://portal.mec.gov.br/cne/ arquivos/pdf/rcp01_06.pdf >. Acesso em: 15 jul. 2009. 
BRZEZINSKI, I. LDB/1996: uma década de perspectivas e perplexidades na formação de profissionais da educação. In: BRZEZINSKI, I. (Org.). LDB dez anos depois: reinterpretações sob diversos olhares. São Paulo: Cortez, 2008a. p. 167-194.

BRZEZINSKI, I. LDB/1996: política de formação de professores - a formação do professor dos anos iniciais do ensino fundamental, desdobramentos em dez anos da Lei n. 9394/1996. In: BRZEZINSKI, I. (Org.). LDB dez anos depois: reinterpretações sob diversos olhares. São Paulo: Cortez, 2008b. p. 195-219.

BRZEZINSKI, I. Políticas contemporâneas de formação de professores para os anos iniciais do ensino fundamental. Educação \& Sociedade, Campinas, v. 29, n. 105, p. 1139-1166, 2008c.

CAMPOS, R. F. Do professor reflexivo ao professor competente: os caminhos da reforma no Brasil. In: MORAES, M. C.; PACHECO, J. A.; EVANGELISTA, O. (Org.). Formação de professores: perspectivas educacionais e curriculares. Porto: Porto Editora, 2003. p. 83-104.

ENS, R. T.; EYNG, A. M.; GISI, M. L. As políticas educacionais e a constituição da representação social do trabalho docente: a percepção de alunos de Pedagogia. In: SOUZA, C. P. de; PARDAL, L. Representações sociais de alunos de Pedagogia e licenciatura sobre o trabalho docente. Aveiro: Ed. Universitária Aveiro, 2009. p. 261-274.

EVANGELISTA, O.; SHIROMA, E. Profissionalização: da palavra à política. In: MORAES, M. C.; PACHECO, J. A.; EVANGELISTA, O. Formação de professores: perspectivas educacionais e curriculares. Porto: Porto Editora, 2003. p. 27-46.

FARTES, V. L. B. Formação profissional, profissões e crise das identidades na sociedade do conhecimento. Cadernos de Pesquisa, São Paulo, v. 38, n. 135, p. 583-585, 2008.

GATTI, B. A.; BARReto, E. S. Professores do Brasil: impasses e desafios. Brasília: Unesco, 2009.

GENTILI, P. A falsificação do consenso: simulacro e imposição na reforma educacional do neoliberalismo no contexto da globalização. Petrópolis: Vozes, 1998. 
LESSARD, C.; TARDIF, M. As transformações atuais do ensino: três cenários possíveis na evolução da profissão do professor? In: TARDIF, M.; LESSARD, C. (Org.). 0 ofício do professor: história, perspectivas e desafios internacionais. Petrópolis: Vozes, 2008. p. 255-278.

GOMES, A. A. Identidades profissionais e representações sociais: a construção das representações sociais sobre "ser professor". In: PARDAL, L. et al. Educação e trabalho: representações, competências e trajectórias. Aveiro: Universidade de Aveiro, 2007. p. 105-123.

GUARESCHI, P. A psicologia social e representações sociais: avanços e novas articulações. In: VERONESE, M. V.; GUARESCHI, P. A. Psicologia do cotidiano: representações sociais em ação. Petrópolis: Vozes, 2007. p. 17-40.

IMBERNÓN, F. Formação docente e profissional: formar-se para a mudança e a incerteza. 3. ed. São Paulo: Cortez, 2002. (Questões da nossa época, v. 77).

JODELET, D. Representações sociais: um domínio em expansão. In: JODELET, D. (Org.). Representações sociais. Rio de Janeiro: EDUERJ, 2001. p. 17-44.

LESSARD, C.; TARDIF, M. As transformações atuais do ensino: três cenários possíveis na evolução da profissão do professor? In: TARDIF, M.; LESSARD, C. (Org.). 0 ofício do professor: história, perspectivas e desafios internacionais. Petrópolis: Vozes, 2008. p. 255-278.

LÜDKE, M.; BOING, L. A. Caminhos da profissão e da profissionalidade docentes. Educação \& Sociedade, Campinas, v. 35, n. 89, p. 1159-1180, 2004.

MARKOVÁ, I. Dialogicidade e representações sociais: as dinâmicas da mente. Tradução de Hélio Magri Filho. Petrópolis: Vozes, 2006.

MOSCOVICI, S. Representações sociais: investigações em psicologia social. Petrópolis: Vozes, 2003.

OLIVEIRA, D. A. A reestruturação do trabalho docente: precarização e flexibilização. Educação \& Sociedade, Campinas, v. 35, n. 89, p. 1137-1144, 2004. 
OLIVEIRA, D. A. Políticas educativas, crise da escola e a promoção de justiça social. In: FERREIRA, E. B.; OLIVEIRA, D. A. Crise da escola e políticas educativas. Belo Horizonte: Autêntica, 2009. p. 17-32.

SOUZA, C. P. de et al. As representações sociais da escola do passado: memória, identidade e trajetórias profissionais de professores. In: PARDAL, L. et al. (Org.). Educação e trabalho: representações, competências e trajectórias. Aveiro: Universidade de Aveiro, 2007. p. 97-104.

SOUZA, C. P. de; VILLAS BÔAS, L. S. Apresentação do estudo: representações sociais sobre o trabalho docente. In: SOUZA, C. P. de; PARDAL, L. A.; VILLAS BÔAS, L. S. (Org.). Representações sociais sobre o trabalho docente. Aveiro: Universidade de Aveiro, 2009. p. 15-30.

TARDIF, M.; LESSARD, C. 0 trabalho docente: elementos para uma teoria da docência como profissão de interações humanas. Petrópolis: Vozes, 2005.

VERONESE, M. V.; GUARESCHI, P. Introdução: articulando representações sociais e cotidiano. In: VERONESE, M. V.; GUARESCHI, P. Psicologia do cotidiano: representações sociais em ação. Petrópolis: Vozes, 2007. p. 9-16.

WEBER, S. Profissionalização docente e políticas públicas no Brasil. Educação \& Sociedade, Campinas, v. 24, n. 85, p. 1125-1154, 2003.

Recebido: 23/12/2010

Received: 12/23/2010

Aprovado: 05/02/2011 Approved: 02/05/2001 